\title{
MRI in 31 patients with Behçet's disease and neurological involvement: prospective study with clinical correlation
}

\author{
B Wechsler, B Dell'lsola, M Vidailhet, D Dormont, J C Piette, O Blétry, P Godeau
}

Service de Médecine Interne

B Wechsler

B Dell'lsola

J C Piette

O Blétry

$P$ Godeau

Service de Neurologie $M$ Vidailhet

Service de

Neuroradiologie

D Dormont

Hôpital de la Pitié-

Salpêtrière

47 Boulevard de

l'Hôpital, 75013

Paris, France

Correspondence to:

Dr B Wechsler, Service de Médecine Interne, Hôpital de la Pitié-Salpêtrière, 47 Boulevard de l'Hôpital, 75013 Paris, France.

Received 19 May 1992 and in revised form 19 August 1992.

Accepted 13 October 1992

Table 1 Main features of Behçet's disease

\begin{tabular}{|c|c|c|c|c|c|}
\hline Case & $\begin{array}{l}\text { Sexl } \\
\text { age }^{\star}\end{array}$ & $\begin{array}{l}\text { Diagnosis } \\
\text { criteria }\end{array}$ & $\begin{array}{l}\text { Pathergy } \\
\text { test }\end{array}$ & $\begin{array}{l}\text { Vascular } \\
\text { thrombosis }\end{array}$ & $\begin{array}{l}\text { Other } \\
\text { features }\end{array}$ \\
\hline 1 & $M / 18$ & O-E & ND & Sural vein & Epididymitis \\
\hline 2 & $W / 48$ & O-G & ND & & Arthritis \\
\hline 3 & $M / 22$ & o-s & + & Sural vein and femoral & \\
\hline 4 & $M / 32$ & O-G-E-S & ND & Sural vein & \\
\hline & $\mathrm{M} / 22$ & O-G-S & + & Sural vein & \\
\hline 6 & $\begin{array}{l}W / 23 \\
W / 33\end{array}$ & O-G & $\begin{array}{l}+ \\
+\end{array}$ & - & \\
\hline $\begin{array}{l}7 \\
8\end{array}$ & $w / 32$ & & $\begin{array}{l}+ \\
+\end{array}$ & Sural vein & \\
\hline 9 & $M / 27$ & O-G-S & + & Pulmonary artery & \\
\hline 10 & M/35 & O-E-S & ND & lliac vein & \\
\hline 11 & $\mathbf{M} / 27$ & O-G-S & ND & - & \\
\hline 12 & $\mathrm{M} / 35$ & O-S & + & - & \\
\hline 13 & $\mathrm{M} / 32$ & O-E-S & + & - & Arthritis \\
\hline 14 & M/38 & O-E-S & ND & - & Arthritis \\
\hline 15 & $\mathbf{M} / 20$ & O-G-E-S & ND & - & Arthritis \\
\hline 16 & M/32 & O-G-S & + & - & Arthritis \\
\hline 17 & $\mathbf{M} / 21$ & O-G-S & + & - & Arthritis \\
\hline 18 & $\mathbf{M} / 22$ & O-G-S & + & - & Arthritis \\
\hline 19 & $\mathrm{~W} / \mathbf{1 0}$ & O-G-E & - & Sural vein & Arthritis \\
\hline 20 & M/19 & O-G-S & + & Femoral vein & \\
\hline 21 & $\mathrm{M} / 34$ & O-G-E-S & + & - & Arthritis \\
\hline 22 & $\mathbf{M} / 33$ & O-G-E-S & ND & - & Arthritis \\
\hline 23 & M/26 & O-G-E-S & ND & - & Arthritis \\
\hline 24 & M/6 & O-G-E & - & - & Epididymitis \\
\hline 25 & $\mathrm{M} / 27$ & O-G-E-S & ND & - & Arthritis \\
\hline 26 & $M / 22$ & O-G-S & ND & Pulmonary artery & \\
\hline 27 & $M / 31$ & O-G-E-S & ND & - & Arthritis \\
\hline 28 & $\begin{array}{l}M / 37 \\
M / 29\end{array}$ & $\begin{array}{l}\text { O-G-E-S } \\
\text { O-G-S }\end{array}$ & $\stackrel{+}{N D}$ & $\overline{\text { Sural yein }}$ & Arthritis \\
\hline $\begin{array}{l}29 \\
30\end{array}$ & $\begin{array}{l}M / 29 \\
W / 29\end{array}$ & $\begin{array}{l}\text { O-G-S } \\
\text { O-G-S }\end{array}$ & $\stackrel{\text { ND }}{+}$ & Brachial and Femoral veins & Arthritis \\
\hline 31 & $\mathbf{M} / 25$ & O-G-E-S & ND & Femoral vein & Arthritis \\
\hline
\end{tabular}

^Age at onset of disease; $\mathrm{O}=$ recurrent oral aphthae; $\mathrm{G}=$ genital aphthae; $\mathrm{E}=$ anterior or posterior uveitis or retinal vasculitis; $S=$ erythema nodosum, pseudofolliculitis, papular or acneiform lesions; $\mathrm{ND}=$ not done.

\begin{abstract}
Thirty one patients with Behçet's disease and neurological manifestations were prospectively studied with MRI. Cerebral venous thrombosis was diagnosed in 10 patients. MRI performed during the acute illness in eight patients showed an abnormally high signal on the $\mathrm{T} 2$ weighted sequences in the occluded sinus. MRI showed minor flow abnormalities suggestive of partial recanalisation of the sinus in two cases at a later clinical stage. MRI can be an alternative, non-invasive, investigation to intravenous cerebral angiography. In 13 patients with central nervous system involvement, MRI performed during the acute illness showed multiple hyperintense lesions on $T 2$ weighted sequences. They were usually less than $5 \mathrm{~mm}$, scattered and confluent, mainly in the white matter, distributed in the hemispheric white matter in nine cases, brainstem in eight, basal ganglia and thalamus in five, and cortex in

two. MRI abnormalities were usually
\end{abstract}

Patients and methods

From 1985 to $1990 \mathrm{MRI}$ was used to study 31 patients with $\mathrm{BD}$ involving the nervous system. All the patients fulfilled the criteria for diagnosis of BD. ${ }^{15}$ There were 25 men and six women, mean (SD) age $26(7 \cdot 6)$ at the onset of BD and 33 (7) years when they presented with neurological symptoms. The main features of $\mathrm{BD}$ are summarised in table 1. Patients were natives of North Africa $(n=17)$, Africa $(n=1)$, Antilles $(n=2)$, Europe $(n=10)$, Turkey $(n=1)$. We tested 28 patients for HLA B5 and it was positive in 10. Neurological involvement was the first manifestation of $\mathrm{BD}$ in three patients (cases $7,10,11$ ) and led to diagnosis of $\mathrm{BD}$ in 15 cases.

MR scanning was performed on a 0.5 Tesla GE-CGR MR unit. Sagittal T1 weighted spin echo sequence (400/21/1-TR/TE/ number of echoes) and axial T2 weighted spin echo sequence (2000-1800/40-60/2-3) were obtained. To detect cerebral venous thrombosis (CVT), frontal T2 weighted (180/60/3) slices were performed. Three successive echoes and a long TE were used in order to avoid flow related enhancement and to differentiate high signal due to thrombosis from even echo rephasing. Each MRI was read by a neuroradiologist (DD) and a neurologist (MV) unaware of the neurological symptoms. When available, CT scans were compared with the MRI scans. Diagnosis of CVT was confirmed on the absence or partial lack of filling of one or several sinuses on at least two projections of bilateral carotid angiography. 
Table 2 Main characteristics of cerebral venous thrombosis

\begin{tabular}{|c|c|c|c|}
\hline Case & Symptoms & Angiography & $M R I$ \\
\hline 1 & IH & right TS & $\begin{array}{l}\text { T1: not done } \\
\text { T2: hypersignal right TS }\end{array}$ \\
\hline 2 & $\begin{array}{l}\text { IH } \\
\text { Monoparesis }\end{array}$ & $\begin{array}{l}\text { SSS } \\
\text { right and left TS } \\
\text { right jugular vein }\end{array}$ & $\begin{array}{l}\text { T1: isosignal } \\
\text { T2: hypersignal SSS } \\
\text { right and left TS }\end{array}$ \\
\hline 3 & IH & SSS and left TS & $\begin{array}{l}\text { T1: isosignal } \\
\text { T2: hypersignal SSS and left TS }\end{array}$ \\
\hline 4 & IH & SSS and right TS & $\begin{array}{l}\text { T1: isosignal } \\
\text { T2: hypersignal SSS and right TS }\end{array}$ \\
\hline 5 & IH & SSS & $\begin{array}{l}\mathrm{T} 1 \text { : isosignal } \\
\mathrm{T} 2 \text { : hypersignal SSS }\end{array}$ \\
\hline 6 & IH & SSS and right TS & $\begin{array}{l}\text { T1: not done } \\
\text { T2: hypersignal SSS and right TS }\end{array}$ \\
\hline 7 & $\begin{array}{l}\text { IH } \\
\text { Hemiparesis } \\
\text { Seizures }\end{array}$ & right TS & $\begin{array}{l}\text { T1: hypersignal right temporoparietal } \\
\text { T2: hypersignal right temporoparietal } \\
\text { and right TS }\end{array}$ \\
\hline 8 & IH & sinus rectus & $\begin{array}{l}\text { T1: isosignal } \\
\text { T2: isosignal }\end{array}$ \\
\hline 9 & IH & SSS, right and left TS & $\begin{array}{l}\text { T1: normal } \\
\text { T2: normal }\end{array}$ \\
\hline 10 & IH & SSS & See table 3 \\
\hline
\end{tabular}

IH = intracranial hypertension; T1 = T1 weighted slices; T2 = T2 weighted slices; SSS = superior sagittal sinus; $\mathrm{TS}=$ transverse sinus. lated intracranial hypertension $(n=8)$. It was associated with focal deficits $(n=2)$ and seizures $(n=1)$. CT scans were normal in five cases, showed a "delta sign" in three cases, and a cerebral infarct caused by venous occlusion in one case. The occlusion of one or several sinuses was demonstrated by cerebral angiography: superior sagittal sinus $(n=7)$, transverse sinus $(n=7)$, sinus rectus and part of Galen's vein $(n=1)$. MRI was performed 16 weeks after the first symptom of CVT (3-44) in eight cases (cases 1-8). An abnormal high signal at the level of the occluded sinus was observed on the T2 weighted sequences (fig 1). The thrombus was isodense to the grey matter on sagittal $\mathrm{T} 1$ weighted images. The comparison of abnormal angiogram and MRI scans in the patient presenting with CVT of the deep cerebral veinous thrombosis revealed the thrombus on the MRI images. In case 7, a hyperintense lesion surrounded by a rim of hypodensity was observed on both $\mathrm{T} 1$ and $\mathrm{T} 2$ weighted images and was compatible with haemorragic infarct of venous origin. This image was surrounded by a high signal area on $\mathrm{T} 2$ weighted sequences (fig 2). All the patients were treated with anticoagulants and corticosteroids. Neurological symptoms improved within four weeks. Control MRI was repeated 2-20 months later in five patients, who became asymptomatic under treatment. Total (case 6) or partial (cases 1-3) recanalisation was observed. In one case (case 7) the thrombus persisted as a hyperintense signal in the occluded sinus.

MRI was performed three and seven years after the first symptom of CVT in two cases (cases 9 and 20). Minor flow abnormalities were detected and were suggestive of partial recanalisation of the sinus.
Figure 1 (case 2) Cerebral venous thrombosis with involvement of the superior sagittal sinus (SSS) and of the right lateral sinus (posterior part). 1 (a) Coronal slice through the posterior part of the SSS (T2 weighted image, $T R=1800, T E=$ 60, first echo), showing hypersignal of thrombosed sinus instead of normal flow void. 1 (b) Same echo, same sequence, coronal slice $3 \mathrm{~cm}$ more anterior showing occlusion of right lateral sinus (arrow); flow void is observed in the SSS which was circulating at this level (more anterior than (a)). 1 (c) Left carotid angiogram (oblique view) showing occlusion of posterior part of SSS (broad arrow) and of right lateral sinus (small arrow) and partial occlusion of left lateral sinus (arrowhead).
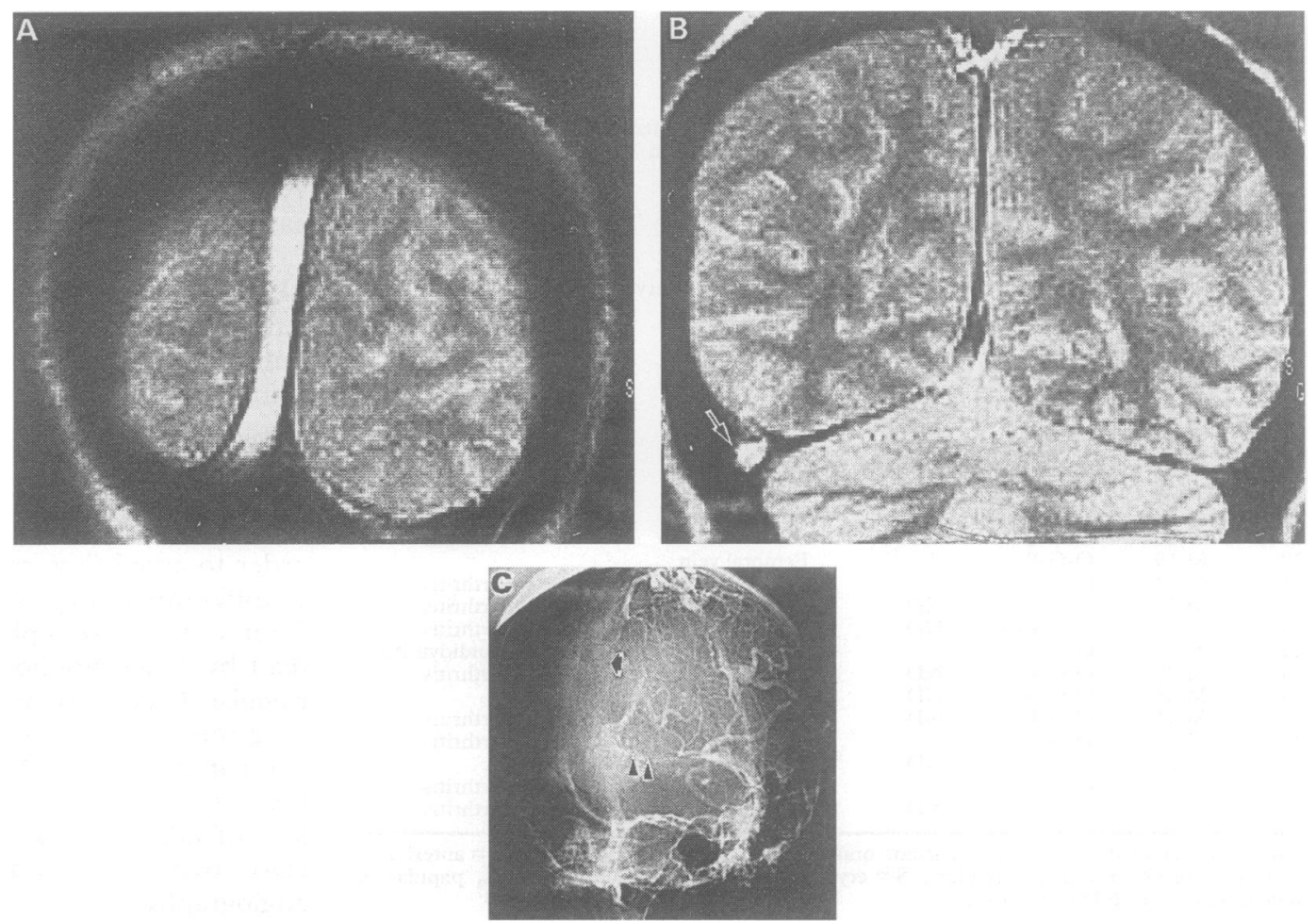
Figure 2 Venous infarction in right temporal lobe associated with right lateral sinus thrombosis (case 7). Axial T2 weighted image $(T R=$ 2000, $T E=40$ ) shows $a$ high signal intensity in the temporal lobe (arrow).

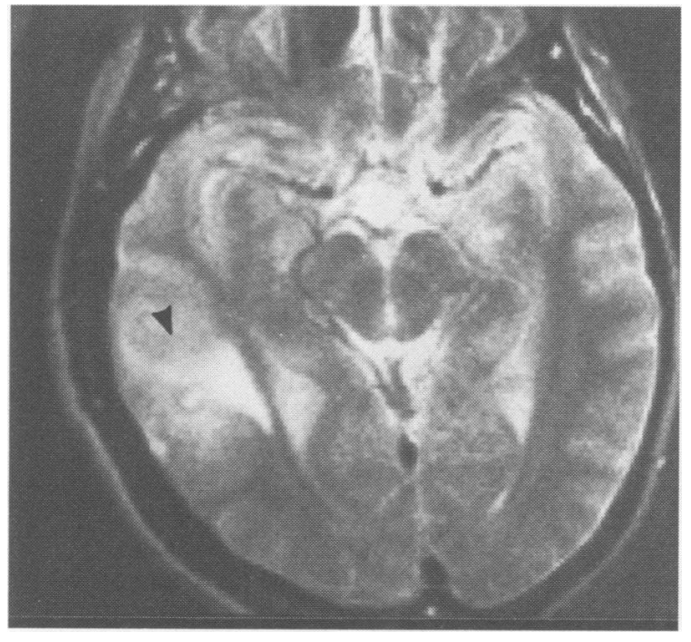

PATIENTS WITH CNS INVOLVEMENT

(CASES 10-24)

CNS involvement was diagnosed in 15 patients. The neurological features are summarised in table 3. Age at onset of neurological symptoms was 33.5 years [mean; standard deviation: $27 \cdot 1-39 \cdot 9]$. In all patients funduscopy was normal. CSF characteristics were: proteins $50 \mathrm{mg} / \mathrm{dl}$ (46-91), lymphocytes 112 $\times 10^{6} / 1$ (5-295). Cerebral angiography, performed in five cases, was normal. CT scan was normal ( $n=7)$, showed mild cerebral atrophy $(n=1)$, focal hypodensity in the temporal lobe $(n=1)$, or in the internal capsule $(\mathrm{n}=2)$.

MRI was performed during the acute illness and was abnormal in $13 / 14$ cases. In seven patients $T 1$ weighted sequence MRIs were considered to be normal or showed mild atrophy $(n=1)$. Nevertheless T2 weighted sequences demonstrated lesions in all the cases but one. They appeared as hyperintense areas and were usually small $(<5 \mathrm{~mm})$, scat- tered, confluent particularly in white matter (figs 3, 4, and 5). MRI lesions were distributed as follows: hemispheric white matter in nine patients $(70 \%)$ (internal capsule $n=6$, corona radiata $n=4$, periventricular white matter $n=4$ ), brainstem in eight patients (60\%) (midbrain $n=5$, pons $n=8$, medulla $\mathrm{n}=1$ ), basal ganglia and thalamus in five patients $(40 \%)$, cortex in two patients. Hemispheric involvement was isolated in only four cases. There was no predilection for the periventricular regions and linear periventricular hyperintensities (cases 11, 16, 23, 24) were always associated with another localisation (table 3). Brainstem lesions always involved the pons (figs 6 and 7). They were isolated in one case and associated with hemispheric lesions in seven cases. Both confluent and punctiform lesions were observed irrespective of vascular territories.

MRI abnormalities were usually associated with appropriate clinical deficits (table 3 ) but they were larger and more disseminated than expected. Cerebellar signs were related to lesions of the afferent or efferent pathways and the cerebellum itself was spared. Lesions of the brainstem were consistently associated with severe neurological impairment such as tetraparesis, pseudobulbar palsy, and bilateral cerebellar signs. Isolated hemispheric involvement was associated in two cases with contralateral hemiparesis or monoparesis. When lesions were bilateral, tetraparesis and pseudobulbar palsy were also observed. In three patients the neurological symptoms could not be related to abnormalities on the MRI. In case 19 the MRI was thought to be normal but the scan was of poor quality because of the patient's excessive movements. A control MRI was obtained (cases 15, 20) at four months and four years after onset of the

Table 3 Main characteristics of central nervous system involvement

\begin{tabular}{|c|c|c|c|}
\hline Case & Clinical features & $M R I$ & Delay \\
\hline $\begin{array}{l}10 \\
11\end{array}$ & $\begin{array}{l}\text { Headache, } R \text { hemiparesis } \\
\text { Dementia, tetraparesis } \\
\text { Cerebellar alaxia, pseudobulbar palsy }\end{array}$ & $\begin{array}{l}\text { Normal } \\
\text { T1: diffuse atrophy } \\
\text { T2: HS periventricular + bilateral internal capsule }\end{array}$ & $\begin{array}{l}13 \text { years } \\
3 \text { years }\end{array}$ \\
\hline 12 & Headache, $R$ hemiparesis & $\begin{array}{l}\text { T1: normal } \\
\text { T2: HS left internal capsule }+ \text { cerebral peduncle }+ \text { pons }\end{array}$ & 6 weeks \\
\hline 13 & $\mathbf{R}$ lower limb monoplegia & $\begin{array}{l}\text { T1: normal } \\
\text { T2: left corona radiata }\end{array}$ & 2 months \\
\hline 14 & Headache, L hemiparesis & $\begin{array}{l}\text { T1: hyposignal pons } \\
\text { T2: HS R thalamus and cerebral peduncle }+ \text { pons }\end{array}$ & 2 months \\
\hline 15 & $\begin{array}{l}\text { Headache, tetraparesis } \\
\text { pseudobulbar palsy }\end{array}$ & $\begin{array}{l}\text { T1: hyposignal pons }+ \text { midbrain } \\
\text { T2: HS } L \text { internal capsule }+ \text { midbrain }+ \text { pons }\end{array}$ & 1 month \\
\hline 16 & $\begin{array}{l}\text { Headache, tetraparesis } \\
\text { cerebellar ataxia }\end{array}$ & $\begin{array}{l}\text { T1: normal } \\
\text { T2: HS periventricular + corona radiata } \\
+R \text { internal capsule and basal ganglia }\end{array}$ & 3 years \\
\hline 17 & $\begin{array}{l}\text { Headache, } \mathbf{L} \text { hemiparesis } \\
\text { cerebellar ataxia, } \mathbf{R} \text { III palsy }\end{array}$ & $\begin{array}{l}\text { T1: not done } \\
\text { T2: diffuse atrophy }\end{array}$ & 10 months \\
\hline 18 & $\begin{array}{l}\text { Dementia, tetraparesis, pseudobulbar palsy } \\
\text { bilateral cerebellar syndrome }\end{array}$ & $\begin{array}{l}\text { T1: hyposignal pons } \\
\text { T2: HS L internal capsule }+ \text { basal ganglia }+ \text { pons }\end{array}$ & 6 months \\
\hline 19 & $\begin{array}{l}\text { Headache, tetraparesis, pseudobulbar palsy } \\
\text { dementia, bilateral cerebellar syndrome }\end{array}$ & Normal & 11 months \\
\hline 20 & $\begin{array}{l}\text { Headache, tetraparesis, pseudobulbar palsy } \\
\text { bilateral cerebellar syndrome } \\
\text { R III + VII + L VI palsy }\end{array}$ & $\begin{array}{l}\text { T1: normal } \\
\text { T2: HS L basal ganglia + midbrain + pons }\end{array}$ & 6 weeks \\
\hline 21 & Headache, R hemiparesis, L VI palsy & $\begin{array}{l}\text { T1: normal } \\
\text { T2: HS R cerebral peduncle }+ \text { pons }+ \text { medulla }\end{array}$ & 4 months \\
\hline 22 & Headache, $\mathbf{L}$ hemiparesis & $\begin{array}{l}\text { T1: hyposignal pons } \\
\text { T2: HS bilateral corona radiata }+ \text { pons }\end{array}$ & 18 months \\
\hline 23 & $\begin{array}{l}\text { Headache, tetraparesis } \\
\text { L cerebellar syndrome }\end{array}$ & $\begin{array}{l}\text { T1: hyposignal bilateral corona radiata } \\
\text { T2: HS bilateral corona radiata }+ \text { parietal cortex }+ \\
\text { L internal capsule }+ \text { basal ganglia }+ \text { periventricular }\end{array}$ & 2 years \\
\hline 24 & Headache, L Hemiparesis & $\begin{array}{l}\text { T1: normal } \\
\text { T2: HS periventricular + bilateral parietal cortex }\end{array}$ & 7 months \\
\hline
\end{tabular}

$\mathrm{R}=$ right; $\mathrm{L}=$ left $\mathrm{HS}=$ hypersignal; $\mathrm{T} 1=\mathrm{T} 1$ weighted slices; $\mathrm{T} 2=\mathrm{T} 2$ weighted slices

*Patient with a history of CVT 3 years before (superior sagittal and transverse sinus are normal); delay = delay between neurological symptoms and performance of MRI 


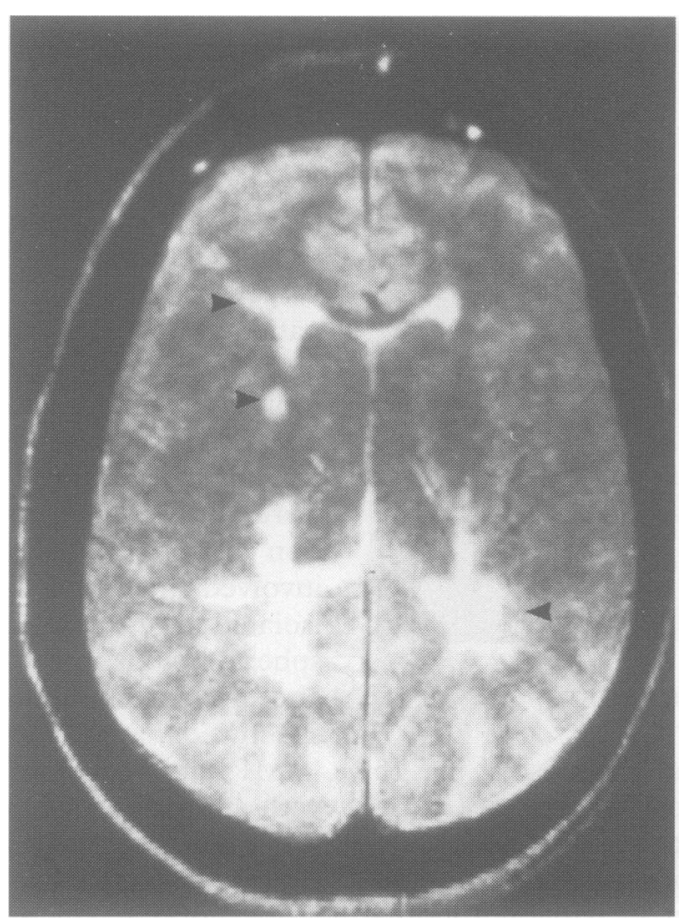

Figure 3 CNS involvement (case 16). Axial T2 weighted image $(T R=2000, T E=40)$ shows foci of high signal intensity in the white matter (arrows).

treatment. No change of the lesions was observed.

In a patient seen 13 years after the onset of the neurological symptoms (case 10), the MRI scan was normal.

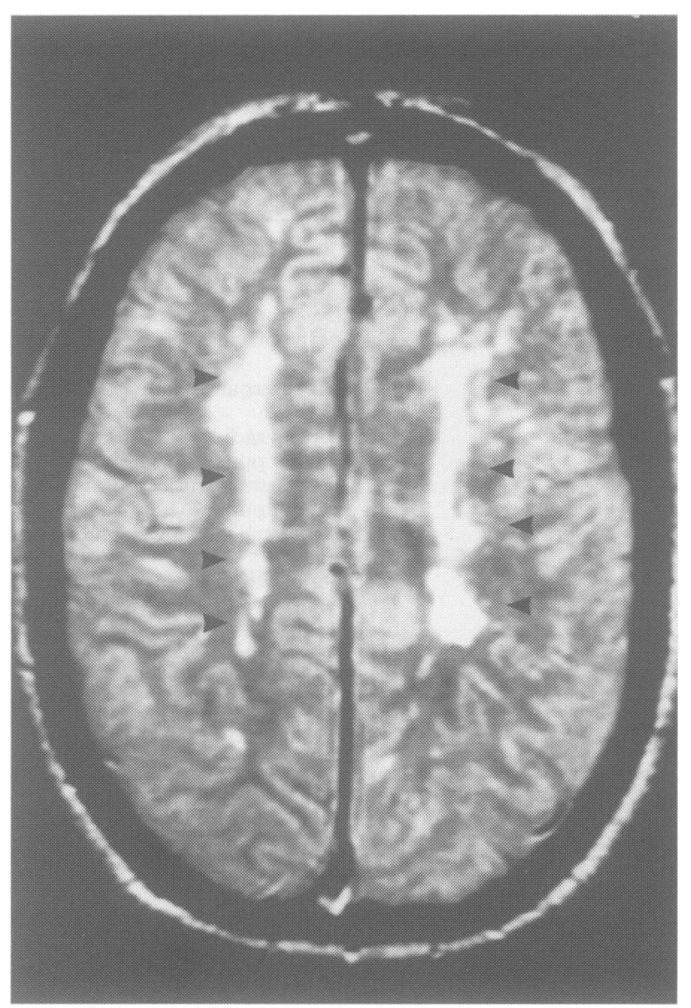

Figure 4 CNS involvement (case 23). Axial T2 weighted image $(T R=2000, T E=40)$ shows multiple bilateral foci of high signal intensity involving the periventricular white matter (arrowheads).

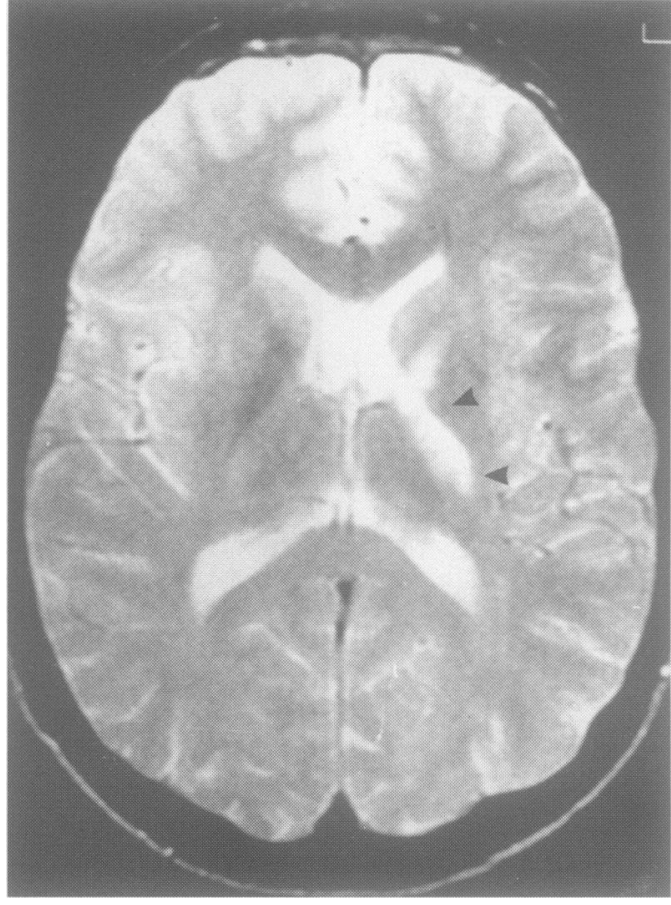

Figure 5 CNS involvement (case 18). Axial T2 weighted image $(T R=2000, T E=40)$ shows high signal intensity in the left pyramidal tract (arrows).

PATIENTS WITH ISOLATED HEADACHE

(CASES 25-31)

Isolated headache, without neurological symptoms or papilloedema, was observed in seven patients. Three had CSF pleiocytosis (lymphocytes $28 \times 10^{6} / 1$ 10-60): CT scan and MRI were normal. Four patients presented with chronic intermittent headache for 10 months to five years. MRI was normal in three. In one patient, a small hyperintense signal was noticed in the left frontal lobe but no neurological symptom appeared during one year of follow up.

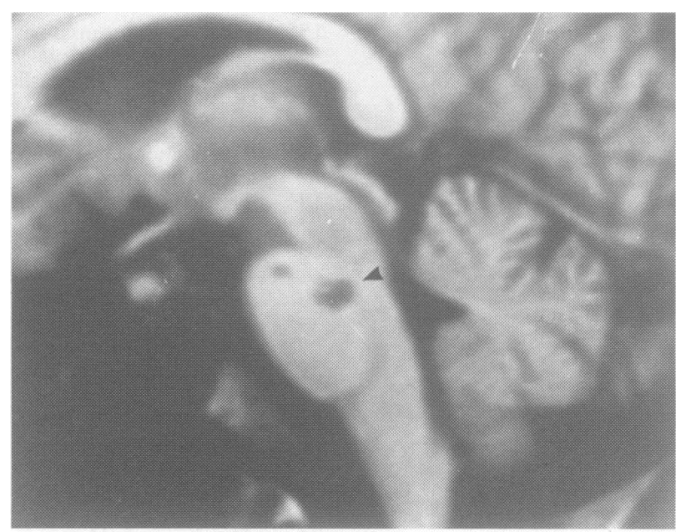

Figure 6 CNS involvement (case 14), sagittal T1 weighted image $(T R=540, T E=10)$ shows a large hyposignal in the pons (arrow). 
Figure 7 CNS involvement (case 20). Axial T2 weighted image $(T R=2000, T E=40)$ shows high signal intensity in the right part of the pons (arrow).

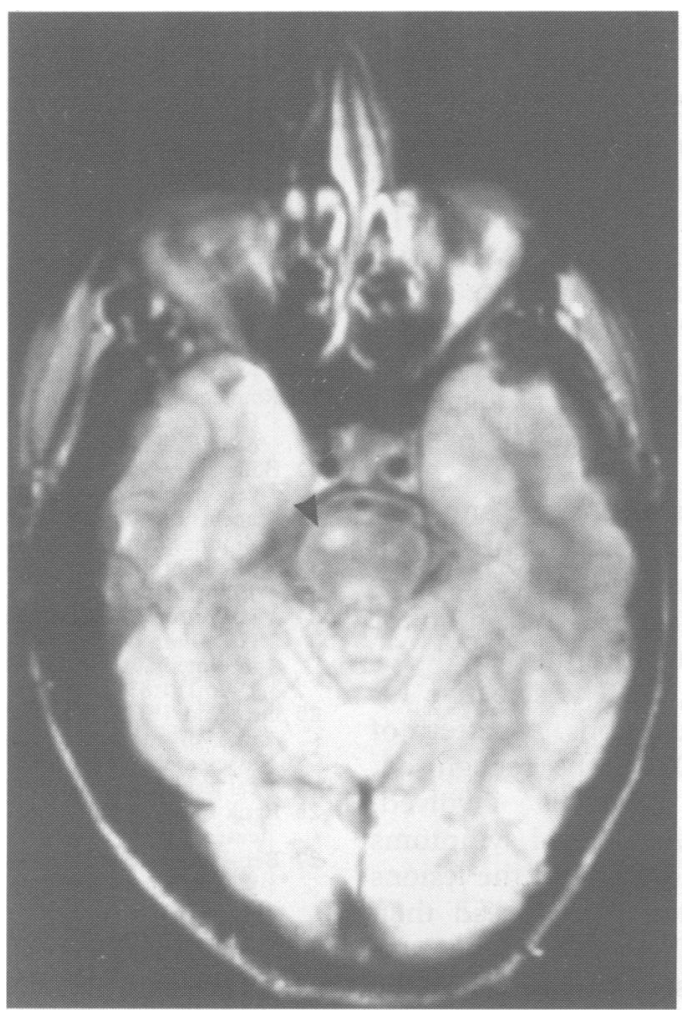

\section{Discussion}

$\mathrm{BD}$, originally described as a syndrome of aphthous stomatitis, genital ulceration, and uveitis, is now recognised as a systemic vasculitis. ${ }^{1718}$ In retrospective studies neurological involvement occurs in $10-50 \%$ of cases. ${ }^{517}$ In a recent Turkish prospective study, Serdaroglu et al estimate the incidence at $5 \cdot 3 \% .^{19}$ It is the presenting symptom in up to $5 \%$ of cases. ${ }^{2021}$ Neurological manifestations of $\mathrm{BD}$ can be divided into three categories ${ }^{21}$ : CVT, CNS involvement, and isolated headache.

CVT is observed in $35 \%$ of patients with neurological manifestations. ${ }^{5}$ Conventional angiography is still required for diagnosis ${ }^{22}$ but MRI has been shown to be a safe and reliable technique in the diagnosis of dural sinus thrombosis. ${ }^{42-25}$ In this series clinical features and imaging are similar to those of patients with CVT of other origin. ${ }^{22}$ Isolated $\mathrm{IH}$ is the usual presentation. Occlusion of several sinuses (including the SSS) is frequent. ${ }^{14192126-31}$ MRI shows direct signs of thrombosis. On T1 weighted slices hypersignals of the occluded sinus have been reported during the first 15 days of evolution. ${ }^{23} 24$ On T2 weighted sequences, abnormal high signal intensity within the affected dural sinuses is observed a few weeks after thrombosis. In pure cortical venous thrombosis or deep cerebral venous thrombosis, the use of contrast agents should be emphasised. More recently, MR angiography has proved helpful in identifying thrombosis with a good correlation with conventional angiography. ${ }^{32}$ Follow up with MRI can demonstrate recanalisation of the occluded sinus and can be used to monitor anticoagulant therapy. ${ }^{33}$

CNS involvement is a severe and devastat- ing manifestation of $\mathrm{BD}$. CT scan may be abnormal in patients with neurological involvement from $\mathrm{BD}^{20}{ }^{34-36}$ but fails to demonstrate small infarcts. ${ }^{37}$ Indeed, MRI is much more sensitive than CT scan. ${ }^{421}$ When CT scan is normal despite neurological symptoms MRI can reveal abnormal signals. When lesions are seen on CT scan, they are larger and more widespread on MRI. ${ }^{938-40}$ The results of our study are consistent with a pattern suggestive of $\mathrm{BD}$.

1 Lesions are usually multiple small foci of high intensity on T2 weighted sequences. They are usually extensive, confluent and distributed over white matter without predilection for the periventricular regions. ${ }^{41}$

2 The lesions are within the white matter $(70 \%)$, the brainstem $(60 \%)$, the basal ganglia and the thalamus $(40 \%)$.

3 Isolated lesions of the cerebral hemispheres can be observed.

4 Lesions of the brainstem are rarely isolated and usually involve the pons.

5 Neurological symptoms are generally correlated with radiological findings as previously reported. ${ }^{21}$ Hypointensity on $\mathrm{T} 1$ and hyperintensity on T2 weighted images can be observed on MRI. When CT scan is normal despite neurological symptoms, MRI can reveal abnormal signals; however, the lesions are more extensive than clinically expected. MRI lesions occur with the same anatomical distribution as the pathological lesions related to vasculitis. ${ }^{9}$ This vasculitis consists of disseminated meningoencephalitis with perivascular cell infiltration, infarction with small necrotic areas surrounding blood vessels, haemorrhage, loss of myelinated fibres, and gliosis. ${ }^{9} 123742$ However, the MRI findings are not specific to $\mathrm{BD}$ and can be observed in other vasculitis of the CNS such as systemic lupus erythematosus ${ }^{12}$; but involvement of the brainstem is rarely observed in systemic lupus erythematosus. ${ }^{4344} \mathrm{BD}$ is also considered in the differential diagnosis of multiple sclerosis (MS) when neurological features are seen in isolation. ${ }^{12}$ The most striking MRI findings are multiple irregular and extensive periventricular lesions. ${ }^{25} 4546$ Nevertheless to differentiate MS from BD on the basis of MRI is difficult. In our experience some features are in favour of BD: MR involvement of basal ganglia and thalamus; the absence of periventricular predominance of the white matter lesions; and the involvement of the pons where hypersignals are mostly observed in the centre part. This is the opposite to MS, where lesions of the brainstem involve the floor of the fourth ventricle and the middle cerebellar peduncles. It must be emphasised that both diseases are diagnosed on a clinical basis. In vasculitis the periventricular changes are often rather mild, hemisphere lesions can be disclosed without periventricular changes, and involvement of grey matter is frequent. ${ }^{12}$

Clinical and radiological correlations have been shown ${ }^{41}$ and resolution of abnormal signals on MRI after treatment has been demonstrated and correlated with clinical improvement. ${ }^{711214347}$ It has been postulated 
that at an early stage of the disease, reversibility of MR lesions in BD may reflect a reversible breakdown in the blood-brain barrier rather than gliosis or infarction. ${ }^{47} \mathrm{We}$ did not observe such imaging reversibility on the two MRIs that we performed on follow up. In patients with isolated headache, MRI was normal in all cases but one. In one case a very small lesion was noticed on MRI and was clinically asymptomatic on follow up without. therapy. Nevertheless, it has been suggested that headache ${ }^{17}$ could herald CNS involvement.

In conclusion, MRI is a sensitive and reliable procedure in $\mathrm{BD}$ with neurological involvement. It can be an alternative to cerebral angiography to diagnose and monitor therapy of cerebral venous thrombosis.

In CNS involvement, MRI is sensitive for the early detection of the lesions. A pattern of lesions evocative of $\mathrm{BD}$ can be recognised, especially when the pons is involved. Correlations between neurological symptoms and MRI lesions can be drawn but the lesions are often larger and more widespread than clinically expected. Further studies with consecutive MRI are necessary to appreciate the effects of treatment on abnormal imaging.

In case of isolated headache, MR helps to rule out neurological involvement, but the abnormalities can be seen in asymptomatic patients.

We are grateful to John Caviness (MD) for his kind assistance and suggestions.

1 Kawakita H, Nishimura $M$, Satoh $Y$, Shibata N Neurological aspects of Behçet's disease. $\mathscr{f}_{p n} \mathcal{F}$ Neurol Sci 1967;5:417-39.

2 Lakhanpal S, Tani K, Lie JT, Katoh K, Ishigatsubo Y, Ohokubo T. Pathologic features of Behçet's syndrome. Human Pathol 1985;16:790-5.

3 Schotland DL, Wolf SM, White HH, Dubin HV Neurologic aspects of Behçet's disease. $A m \mathcal{F} \mathrm{Med}$ 1963;34:544-53.

4 Willeit J, Schmutzhard E, Aichner F, Mayr U, Weber F, Gerstenbrand F. CT and MR imaging in neuro-Behçet disease. $\mathcal{f}$ Comput Assist Tomogr 1986;10:313-5.

5 Wolf SM, Schotland DL, Phillips LL. Involvement of nervous system in Behçet's syndrome. Arch Neurol 1965; 12:315-25.

6 Chajek T, Fainaru M. Behçet's disease. Report of 41 cases and a review of the literature. Medicine 1975;54: 179-95.

7 Patel DV, Neuman MJ, Hier DB. Reversibility of CT and MR findings in neuro-Behçet disease. $\mathcal{F}$ Comput Assist Tomogr 1989;13:669-73.

8 Besana C, Comi G, Del Maschio A, et al. Electrophysiological and MRI evaluation of neurological involvement in Behçet's disease. $f$ Neurol Neurosurg Psychiatry 1989;52:749-54.

9 Fukuyama $H$, Kameyama $M$, Nabatame $H$, et al. Magnetic resonance images of neuro-Behçet syndrome show precise brain stem lesions. Acta Neurol Scand
$1987 ; 75: 70-3$.

10 Kataoka S, Hirose G, Tsukada K. Brain stem type neuroBehçet's syndrome. Neuroradiology 1989;31:258-62.

11 Kermode AG, Plant GT, Mac Manus DG, Kendall BE Kingsley DPE, Moseley IF. Behçet's disease with slowly enlarging midbrain mass on MRI: Resolution following steroid therapy. Neurology 1989;39:1251-2.

12 Miller DH, Ormerod IEC, Gibson A, Du Boulay EPG, Rudge P, MacDonald WI. MR brain scanning in patients with vasculitis: differentiation from multiple sclerosis. Neuroradiology 1987;29:226-31.

13 Shakir RA, Sulaiman K, Kahn RA, Rudwan M Neurological presentations of neuro-Behcet's syndrome: clinical categories. Eur Neurol 1990;30:249-53.

14 Snyder TC, Sachdev HS. MR imaging of cerebral dural sinus thrombosis. If Comput Assist Tomogr 1986;10 889-91.

15 International Study Group for Behçet's Disease. Criteria for diagnosis of Behçet's disease. Lancet 1990;335:
1078-80.

16 Wechsler B, Vidailhet M, Piette JC, et al. Cerebral venous thrombosis in Behcet's disease: clinical study and long term follow up of 25 cases. Neurology 1992;42:614-8.

17 O'Duffy JD, Goldstein NP. Neurologic involvement in seven patients with Behçet's disease. Am $\mathcal{F}$ Med 1976 61:170-8

18 Shimizu T, Ehrlich GE, Inaba G, Hayashi K. Behçet disease. Semin Arthritis Rheum 1979;8:223-60.

19 Serdaroglu P, Yazici H, Ozdemir C, Yurdakul S, Bahar S, Atkin E. Neurologic involvement in Behçet's syndrome. Arch Neurol 1989;46:266-9.

20 Kozin F, Haughton V, Bernhard GC. Neuro-Behçet disease: two cases and neuroradiologic findings. Neuroradiology 1977;27:1148-52.

21 Rougemont D, Bousser MG, Wechsler B, Blétry $O$ Castaigne $\mathbf{P}$, Godeau P. Manifestations neurologiques de la maladie de Behçet. Rev Neurol 1982;138:496-505.

22 Bousser MG, Chiras J, Bories J, Castaigne P. Cerebra venous thrombosis. Stroke 1985;16:199-213.

23 Macchi PJ, Grossman RI, Gomori JM, Goldberg HI, Zimmerman RA, Bilaniuk LT. High field MR imaging of cerebral venous thrombosis. $\mathcal{F}$ Comput Assist Tomog 1986;10:10-5.

24 Mac Murdo SK, Brant-Zawadzki M, Bradley WG, Chang GY, Berg BO. Dural sinus thrombosis: study using intermediate field strength $\mathrm{MR}$ imaging. Radiology
1986;161:83-6.

25 Ormerod IEC, Miller DH, Mac Donald WI, et al. The role of nuclear magnetic resonance imaging in the assessment of multiple sclerosis and isolated neurological lesions. Brain 1987;110:1579-616.

26 Bank I, Weart C. Dural sinus thrombosis in Behçet's disease. Arthritis Rheum 1984;27:816-8.

27 Ben-Itzhak J, Keren S, Simon J. Intracranial venous thrombosis in Behçet's syndrome. Neuroradiology 1985; 27:450.

28 Brissaud P, Laroche L, de Gramont A, Krulik M. Digital angiography for the diagnosis of dural sinus thrombosi in Behçet's disease. Arthritis Rheum 1985;28:359-60.

29 Feuilhade C, Touboul JL, Wechsler B, Guillard A Thrombophlébite cérébrale au cours de la maladie de Behçet. Presse Med 1982;11:3351.

30 Harper CM, O'Neill BP, O'Duffy JD, Forbes GS. Intracranial hypertension in Behçet's disease: demonstration of sinus occlusion with use of digital subtraction angiography. Mayo Clin Proc 1985;60:419-22.

31 Masheter HC. Behçet's syndrome complicated by intracranial thrombophlebitis. Proc Roy Soc Med 1959; 52:1039-40.

32 Payadachee TS, Bingham JB, Graves MJ, et al. Dural sinus thrombosis: diagnosis and follow-up by magnetic resonance, angiography and imaging. Nexroradiology 1991;33:165-7.

33 Einhaeupl KM, Villringer A, Meister W, et al. High dose heparin treatment in cerebral sinus venous thrombosis. Lancet 1991;338:597-600.

34 Dobkin BH. Computerized tomographic findings in neuro-Behçet's disease. Arch Neurol 1980;37:58-9.

35 Herskovitz S, Lipton RB, Lantos G. Neuro-Behçet's disease: CT and clinical correlates. Neurology 1988;38: 1714-20.

36 Litvan I, Roig C, Rovira A, Ruscalleda J. Behçet's syndrome masquerading as tumor. Neuroradiology 1987; 29:103.

37 Kuroiwa $Y$, Tohgi $H$, Kanayama $H$, Fujimori M, Aoki $H$. Neuro-Behçet's disease with alternating hemiparesis. Neuroradiology 1986;28:284.

38 Vidaller A, Carratala J, Moreno R, Arbizu T, Rubio F. Magnetic resonance imaging in neuro-Behçet's disease. $\mathrm{Br} \mathcal{F}$ Rheum 1987;27:79-80.

39 Wechsler B, Dormont D, Lubetski C, et al. Magnetic resonance imaging in Behçet's disease. In: JD O'Duffy, E Kokmen, eds. Behcet's disease, basic and clinical aspects. New York: Marcel Dekker, 1991:331-4.

40 Zuheir Al Kawi M, Bohlega S, Banna M. MRI findings in neuro-Behçet's disease. Neurology 1991;41:405-8.

41 Banna $M$, El Ramahl $K$. Neurologic involvement in Behçet disease: imaging findings in 16 patients. Am $\mathcal{F}$ Neuroradiol 1991;2:791-6.

42 Iseki E, Iwabuchi K, Yagishita S, Amano N, Matsushita M. Two necropsy cases of chronic encephalomyelitis: M. Two necropsy cases of chronic encephalomyelitis:
variants of neuro-Behcet's disease? $₹$ Neurol Neurosurg variants of neuro-Behçet's
Psychiatry 1988;51:1084-7.

43 Mc Abee GN, Barasch ES. Resolving MRI lesions in lupus erythematosus selectively involving the brain stem. Pediatr Neurol 1990;6:186-9.

44 Suzuki K, Hara M, Nakajima S, et al. Analysis of systemic lupus erythematosus (SLE) involving the central nervous system by magnetic resonance imaging (MRD). Ryumachi 1989;29:88-96.

45 Paty DW, Oger JJ, Kastrukoff LF, et al. Nuclear magnetic resonance imaging in the diagnosis of multiple sclerosis. Neurology 1988;38:180-5.

46 Steward JM, Houser OW, Baker HL, O'Brien PC, Rodriguez M. Magnetic resonance imaging and clinical relationships in multiple sclerosis. Mayo Clin Proc 1987; 62:174-84.

47 Pamir MN, Kansu T, Erbengi A, Zileli T. Papilledema in Behçet's syndrome. Arch Neurol 1981;38:643-5. 